0271-5198(95)00029-1

\title{
CONTENTS OF BIORHEOLOGY, VOLUME 32, NUMBER 1
}

Contents

P. E. Prete, A. Gurakar-Osborne and
M. L. Kashyap
J. L. Bert and R. K. Reed
D. W. Sutton and
G. W. Schmid-Schönbein
T. Naiki, K. Hayashi and S. Takemura

T. W. Taylor and T. Yamaguchi

K. Konstantopoulos, K. K. Wu M. M. Udden, E. I. Bañez, S. J. Shattil and J. D. Hellums
Review

1 Synovial fluid lipids and apolipoproteins: A contemporary perspective

Papers

17 Flow conductivity of rat dermis is determined by hydration

29 The pressure-flow relation in resting rat skeletal muscle perfused with pure erythrocyte suspensions

43 An LDA and flow visualization study of pulsatile flow in an aortic bifurcation model

61 Flow patterns in three-dimensional left ventricular systolic and diastolic flows determined from computational fluid dynamics

73 Flow cytometric studies of platelet responses to shear stress in whole blood

$95 \quad$ Erratum

$97 \quad$ Announcements

99 Contents of Clinical Hemorheology, Volume 14, Number 4 